\title{
Inhibition of Hedgehog signalling by NVP-LDE225 (Erismodegib) interferes with growth and invasion of human renal cell carcinoma cells
}

C D'Amato ${ }^{1}, \mathrm{R}$ Rosa ${ }^{1}, \mathrm{R}$ Marciano ${ }^{1}, \mathrm{~V} \mathrm{D}^{\prime}$ Amato $^{1}$, L Formisano ${ }^{1}, \mathrm{~L}$ Nappi ${ }^{1}, \mathrm{~L}$ Raimondo ${ }^{1}, \mathrm{C}$ Di Mauro ${ }^{1}$, A Servetto ${ }^{1}$, F Fulciniti ${ }^{2}$, A Cipolletta ${ }^{2}$, C Bianco $^{3}$, F Ciardiello ${ }^{4}$, B M Veneziani ${ }^{5}$, S De Placido ${ }^{1}$ and R Bianco*,1

${ }^{1}$ Cattedra di Oncologia Medica, Dipartimento di Medicina Clinica e Chirurgia, Università di Napoli "Federico II", Via S. Pansini 5, Napoli 80131, Italy; ${ }^{2}$ Anatomia Patologica e Citopatologia, Istituto Nazionale Tumori 'Fondazione G. Pascale', IRCCS, Napoli 80131, Italy; ${ }^{3}$ Radioterapia, Istituto Nazionale Tumori 'Fondazione G. Pascale', IRCCS, Napoli 80131, Italy; ${ }^{4}$ Dipartimento MedicoChirurgico di Internistica Clinica e Sperimentale 'F. Magrassi e A. Lanzara', II Universitá degli Studi di Napoli, Napoli 80131, Italy and ${ }^{5}$ Dipartimento di Medicina Molecolare e Biotecnologie Mediche, Università di Napoli "Federico II", Napoli 80131, Italy

Background: Multiple lines of evidence support that the Hedgehog $(\mathrm{Hh})$ signalling has a role in the maintenance and progression of different human cancers. Therefore, inhibition of the Hh pathway represents a valid anticancer therapeutic approach for renal cell carcinoma (RCC) patients. NVP-LDE225 is a Smoothened (Smo) antagonist that induces dose-related inhibition of Hh and Smo-dependent tumour growth.

Methods: We assayed the effects of NVP-LDE225 alone or in combination with everolimus or sunitinib on the growth and invasion of human RCC models both in vitro and in vivo. To this aim, we used a panel of human RCC models, comprising cells with acquired resistance to sunitinib - a multiple tyrosine kinase inhibitor approved as a first-line treatment for RCC.

Results: NVP-LDE225 cooperated with either everolimus or sunitinib to inhibit proliferation, migration, and invasion of RCC cells even in sunitinib-resistant (SuR) cells. Some major transducers involved in tumour cell motility, including paxillin, were also efficiently inhibited by the combination therapy, as demonstrated by western blot and confocal microscopy assays. Moreover, these combined treatments inhibited tumour growth and increased animal survival in nude mice xenografted with SuR RCC cells. Finally, lung micrometastasis formation was reduced when mice were treated with NVP-LDE225 plus everolimus or sunitinib, as evidenced by artificial metastatic assays.

Conclusions: Hedgehog inhibition by NVP-LDE225 plus sunitinib or everolimus bolsters antitumour activity by interfering with tumour growth and metastatic spread, even in SuR cells. Thus, this new evidence puts forward a new promising therapeutic approach for RCC patients.

Human renal cell carcinoma (RCC) is a highly vascularised tumour involving high levels of vascular endothelial growth factor (VEGF) and other proangiogenic factors. However, some subtypes of RCC have also been correlated with alterations in cellular signalling pathways. For instance, papillary RCC is often associated with alterations in signalling pathways that depend on the Met tyrosine

*Correspondence: Dr R Bianco; E-mail: robianco@unina.it

Received 27 March 2014; revised 1 July 2014; accepted 3 July 2014; published online 5 August 2014 (c) 2014 Cancer Research UK. All rights reserved 0007 - 0920/14

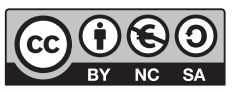

B) $\mathrm{C} \cap$ 
kinase membrane receptor. Still, other subtypes are due to genetic alterations. A case in point is clear cell renal carcinoma, the most common form of renal cancer, representing 75\% of all RCCs. In particular, this RCC subtype has been attributed to deletion of the von Hippel Lindau (VHL) gene (Finley et al, 2011) - an event that causes hyperactivity of the hypoxia inducible factor 1 and production of angiogenic factors, such as VEGF and plateletderived growth factor (PDGF; Amato, 2005; Rini and Small, 2005; Barthélémy et al, 2013). Several therapies directed against VEGF and the mammalian target of rapamycin (mTOR) pathways have become a standard of care in metastatic RCC. For instance, sunitinib is currently being used as a first-line treatment for metastatic RCC. In particular, this oral multi-targeted receptor tyrosine kinase inhibitor (TKI) works by targeting various receptors, including VEGFRs and PDGFRs (Motzer et al, 2007). Another selective analogue is everolimus (RAD001). This oral drug selectively inhibits mTOR - a serine-threonine kinase that regulates cellular metabolism, growth, proliferation, and angiogenesis. Despite the improved outcomes observed in clinical trials using VEGF-targeted therapies, several important treatment issues need to be considered. For instance, the survival benefit is still extremely inconsistent among patients. Furthermore, the adverse effects following such treatments often limit the administration of such inhibitors and no predictive biomarkers have yet been validated. In addition, resistance to VEGFRs and mTOR blocking agents often arises even in responders, most likely because of altered signalling alterations. Among these are endothelial genomic instability, ineffective target inhibition, hypoxia inducible factor 1 upregulation with downstream effects on proangiogenic signalling molecules, activation of alternative angiogenic pathways, and mTORC2 upregulation (Rini and Atkins, 2009).

The Hedgehog $(\mathrm{Hh})$ signalling pathway, which is broadly active in early embryonic development, orchestrates tissue patterning in vertebrates and invertebrates. Later in life, Hh signalling is however restricted, and, in adulthood, it presumably maintains stem cell populations and/or early progenitor cells. The Hh pathway can be stimulated by three Hh ligands: sonic hedgehog (Shh), Indian hedgehog (Ihh), or Desert hedgehog (Dhh). When these ligands bind to Patched (Ptch), a 12-pass transmembrane protein that functions as a repressor of the pathway, the inhibition of Smoothened (Smo) by Ptch is relieved. Activated Smo in turn initiates a downstream signalling cascade leading both to the activation of transcription factors belonging to the Gli family (Gli$1,2,3)$ and to the transcription of Gli target genes such as GLI-1, PTCH, HIP1, D-type cyclins, BMI1, and BCL2 (Teglund and Toftgård, 2010). To date, multiple lines of evidence support the idea that $\mathrm{Hh}$ signalling has a role in the maintenance and progression of several human cancers, including medulloblastoma, basal cell carcinoma (BCC), lung, pancreatic, breast, and renal cancers. Nonetheless, its underlying molecular mechanisms of action still remain controversial. What is known so far, however, is that the Hh signalling pathway is altered in pancreatic and colorectal cancers, and melanomas (Chari and McDonnell, 2007). These pathologies are coupled with increased expression of numerous target genes that regulate various processes including cell proliferation, cell differentiation and cell death, extracellular matrix interactions, and angiogenesis (Louro et al, 2002). Shh/Gli-1 pathway components have also been correlated with the promotion of epithelial-to-mesenchymal (EMT) transition - a process that is associated with increased invasion and metastatic capabilities (Yue et al, 2014). In human RCC, the Hh signalling pathway is often constitutively reactivated in tumours independently of the expression of the VHL tumour suppressor gene (Dormoy et al, 2009). Indeed, evidence for $\mathrm{Hh}$ involvement is that, whereas Shh recombinant treatment enhances RCC cell proliferation, treatment with the Smo inhibitor cyclopamine inhibits tumour growth (Behnsawy et al, 2013), causes decreased invasion, and impairs metastatic potential, events that are mediated by the downregulation of Neuropilin-1 - a proangiogenic cell surface glycoprotein (Cao et al, 2008).

Based on this corroborating evidence, scientists have put forward the hypothesis that the inhibition of the Hh pathway could constitute an effective therapeutic approach against cancer. In this regard, few drugs have so far been investigated for their potential inhibitory activity. Cyclopamine, one of the first drugs to be tested for its Hh signal inhibitory properties, acts by selectively binding to Smo (Lipinski et al 2008), thereby inhibiting cell proliferation and inducing apoptosis in cancer cells with reactivated Hh/Gli (Han et al, 2009; Shigemura et al, 2011). Another Smo antagonist is GDC-0449 (vismodegib). This small molecule, which also selectively binds to Smo, blocks intracellular signalling through inhibition of Gli-1 and related targeted genes, thereby interfering with tumour growth and survival. Remarkably, vismodegib is the first $\mathrm{Hh}$ inhibitor to have been clinically approved by the FDA for the treatment of BCC. In a recent multicentre open-label phase II trial, it produced a response rate of $30 \%$ in patients with metastatic BCC and of $43 \%$ in patients with locally advanced BCC, whereas complete response was seen in $21 \%$ of patients with locally advanced BCC (Sekulic et al, 2012). Owing to these encouraging results, it is currently under clinical evaluation for an array of other cancer types including metastatic colorectal cancer, small-cell lung cancer, gastric cancer, pancreatic cancer, medulloblastoma, and chondrosarcoma (Fellner, 2012). However promising and encouraging these results are, there is still a pressing need in clinical and preclinical research to gain a deeper understanding of the mechanisms underlying the phenomenon of drug resistance in several cancer types including RCC. The lack of a successful therapeutic strategy that could actually overcome RCC acquired resistance to targeted agents was what prompted us to investigate the role of $\mathrm{Hh}$ signalling. In this study, we evaluated the effects of NVP-LDE225 (erismodegib) - a selective and orally bioavailable Smo antagonist that inhibits the $\mathrm{Hh}$ signalling pathway via antagonism of the Smo receptor (Fendrich et al, 2011) - on growth and invasion of human RCC cell lines, both in vitro and in vivo. Equally important, we examined whether NVP-LDE225 combined with sunitinib or everolimus could emerge as a novel therapeutic strategy potentially able to overcome RCC resistance to sunitinib.

\section{MATERIALS AND METHODS}

Compounds. NVP-LDE225, everolimus, sunitinib, and GANT-61 were purchased from Selleck Chemicals, Munich, Germany.

Cell cultures. ACHN, 786-O and 769-P human clear RCC cell lines were obtained from the American Type Culture Collection (Manassas, VA, USA) and were maintained as previously described (Damiano et al, 2013). 786-O SuR (sunitinib-resistant) cells were generated through a validated protocol of in vivo/in vitro selection, as described in the animal study section.

MTT survival assay. Cells $\left(10^{4}\right.$ cells per well) were grown in 24well plates and exposed to increasing doses of NVP-LDE225, everolimus, and sunitinib, alone or in combination. The percentage of cell survival was determined using the 3-(4,5-dimethylthiazol-2yl)-2,5-diphenyltetrazolium bromide (MTT).

Western blot analysis. Cell protein extracts were prepared from tumour cells cultured for $24 \mathrm{~h}$ in the presence or absence of NVPLDE225 $(2.5 \mu \mathrm{M})$, everolimus $(1 \mu \mathrm{M})$, and sunitinib $(1 \mu \mathrm{M})$. Total cell lysates from cell cultures or tumour specimens were resolved by $4-15 \%$ SDS-PAGE and probed with anti-human monoclonal Gli-2, pMAPK, MAPK, Vimentin, N-cadherin and E-cadherin (Santa Cruz Biotechnology, Santa Cruz, CA, USA), polyclonal Gli-1, 
p-paxillin, paxillin, pAkt and Akt (Cell Signaling Technologies, Beverly, MA, USA), monoclonal pp70S6K and p70S6K (Upstate Millipore, Billerica, MA, USA) and monoclonal actin (SigmaAldrich, Milan, Italy). Immunoreactive proteins were visualised by enhanced chemiluminescence (Pierce, Rockford, IL, USA) (Nardone et al, 2011). Densitometric analyses were performed with ImageJ software (US National Institutes of Health, Bethesda, MD, USA); results were normalised for $\beta$-actin.

Wound-healing assay. Cancer cell line monolayers, grown to confluence on gridded plastic dishes, were wounded by scratching them with a $200-\mu$ l pipette tip and then cultured in the presence or absence of NVP-LDE225 $(2.5 \mu \mathrm{M})$, everolimus $(0.5 \mu \mathrm{M})$, and sunitinib $(1 \mu \mathrm{M})$ for $24 \mathrm{~h}$. Under these conditions, all drugs inhibited cell proliferation. The wounds were photographed ( $\times 10$ objective) at 0 and $24 \mathrm{~h}$, and healing was quantified by measuring the distance between the edges using Adobe Photoshop (v.8.0.1; Adobe Systems, Inc., San Jose, CA, USA). The results are presented as the percentage of the total distance of the original wound enclosed by cells.

Invasion assay. NIH3T3 murine fibroblasts monolayers were grown to confluence in 24-well plates and permeabilised with $500 \mu \mathrm{l}$ per well DMSO for $1 \mathrm{~h}$. Renal cell carcinoma cells were juxtaposed on fibroblast monolayers and allowed to grow in the presence or absence of NVP-LDE225 $(2.5 \mu \mathrm{M})$, everolimus $(0.5 \mu \mathrm{M})$, and sunitinib $(1 \mu \mathrm{M})$. After $24 \mathrm{~h}-96 \mathrm{~h}$, cells were first incubated with $0.2 \%$ trypan blue/phosphate-buffered saline (PBS) for $15 \mathrm{~min}$ and then lysed with $100 \mu \mathrm{l}$ of $1 \%$ SDS/PBS. Finally, to quantify invasion, absorbance was measured at $610 \mathrm{~nm}$.

Drop evasion assay. Renal cell carcinoma cells were harvested from culture according to standard protocols. Cell concentration was then adjusted to $\sim 5000$ cells per $\mu \mathrm{l}\left(5 \times 10^{6} \mathrm{ml}^{-1}\right)$. Matrigel was added to the cell suspension (ratio 2:1). Drops of the cell/ matrigel suspension were formed in six-well plates and were incubated for $\sim 30 \mathrm{~min}$ at $37^{\circ} \mathrm{C}$ until solidification. After addition of complete medium $(2 \mathrm{ml})$, cells were treated with NVP-LDE225 $(2.5 \mu \mathrm{M})$, everolimus $(0.5 \mu \mathrm{M})$, and sunitinib $(1 \mu \mathrm{M})$. After $24-48 \mathrm{~h}$, pictures of each drop were taken.

Determination of VEGF concentrations through enzyme-linked immunosorbent assay. Anti-human VEGF (hVEGF) polyclonal antibody ( $\& \& D$ Systems, Minneapolis, MN, USA), diluted at $1 \mu \mathrm{g} \mathrm{ml}^{-1}$ in PBS, pH 7.5, was used to coat a 96-well plate, $100 \mu \mathrm{l}$ per well, overnight at $4{ }^{\circ} \mathrm{C}$. Washings, dilutions of standards (recombinant hVEGF) and samples (tumour extracts of killed mice), biotinylation, and mixtures with preformed avidin and biotinylated HRP macromolecular complex (Vectastain kit) were performed as previously described (Errico et al, 2004). Absorbance was measured at $490 \mathrm{~nm}$ on a microplate reader (Bio-Rad, Hercules, CA, USA). Vascular endothelial growth factor concentrations were determined by interpolation of the standard curve using linear regression analysis.

Nude mice cancer xenograft models. For in vivo studies, 786-O $\mathrm{SuR}$ cells were used. These cells were obtained through a validated protocol of in vivo/in vitro selection following daily exposure to the drug, as recently described (Monteleone et al, 2013). Briefly, 786-O cells were injected subcutaneously (s.c.) into nude mice. Then, when tumours reached the size of $\sim 1 \mathrm{~cm}^{3}$, mice were treated once daily with sunitinib $\left(40 \mathrm{mg} \mathrm{kg}^{-1}\right)$ for 8 weeks. Tumours progressing under treatment with sunitinib were excised and then digested with a specific enzymatic solution. Afterwards, tumour cells were recovered for in vitro growth and evaluated for sensitivity to sunitinib using MTT assay. Cells growing despite the presence of the drug $(5 \mu \mathrm{M})$ were considered resistant. Five-week-old Balb/c athymic $(\mathrm{nu}+/ \mathrm{nu}+)$ nude mice (Charles River Laboratories, Milan, Italy) were maintained in accordance with the institutional guidelines of the University of Naples Animal Care Committee. In brief, they were injected s.c. with $786-\mathrm{O}$ SuR cells $\left(10^{7}\right.$ cells per mice) re-suspended in $200 \mu \mathrm{l}$ of Matrigel (CBP, Bedford, MA, USA). Fourteen days later, when tumours reached the volume of $\sim 0.5 \mathrm{~cm}^{3}$, groups of 10 mice each were randomised to receive the following medications: NVP-LDE225 $\left(20 \mathrm{mg} \mathrm{kg}^{-1}\right.$, p.o.) once daily for 3 weeks, everolimus ( $5 \mathrm{mg} \mathrm{kg}^{-1}$, p.o.) once daily for 3 weeks, sunitinib ( $40 \mathrm{mg} \mathrm{kg}^{-1}$, i.p.) once daily for 3 weeks, or their combinations. Tumour volume $\left(\mathrm{cm}^{3}\right)$ was measured using the formula $\pi / 6 \times$ larger diameter $\times$ (smaller diameter $)^{2}$, as previously reported (Rosa et al, 2013).

Experimental metastasis assay. Before inoculation with 786-O SuR cells, mice (six mice per group) were treated with either NVPLDE225 (20 $\mathrm{mg} \mathrm{kg}^{-1}$ p.o.), everolimus ( $5 \mathrm{mg} \mathrm{kg}^{-1}$ p.o.), sunitinib (40 $\mathrm{mg} \mathrm{kg}^{-1}$ i.p.), or their combinations. Mice were inoculated with $30 \times 10^{5}$ cells via tail vein injection, followed by treatment with NVP-LDE225, everolimus, sunitinib, or their combination for 7 consecutive days. All mice were killed on day 21 (Liu et al, 2012). Human DNA in mouse lungs was measured by quantifying Alu sequences through PCR, as previously described (Schneider et al, 2002).

Immunohistochemical assay. Excised tumours were split in two halves and immediately fixed in $10 \%$ buffered formalin solution. Twelve hours later, tissues were embedded in paraffin in an automated tissue processor. Sections $(4-5 \mu \mathrm{m})$ were then cut with a serial microtome and mounted on adhesive poly-L-lysine-coated slides. After being dried in an oven at $40^{\circ} \mathrm{C}$ for $8 \mathrm{~h}$, the slides were processed for immunohistochemistry (IHC) in a semi-automated machine (Menarini Bond Max, Menarini, Florence, Italy) with the following antibodies: Vimentin, Mib-1, and CD31 (Novocastra, Newcastle, UK). IHC scores for Vimentin were obtained by multiplying the intensity of cytoplasmic staining $(1+$ for weak, $2+$ for moderate, and $3+$ for strong staining) by the percentage of positive neoplastic cells, as measured on 10 contiguous high power $(\times 40)$ microscopic fields $(\mathrm{HPF})$. Similarly, IHC scores for CD31 were obtained by multiplying the intensity of cytoplasmic staining $(1+$ for weak, $2+$ for moderate, and $3+$ for strong staining) by the percentage of tumour vessels. Finally, IHC scores for Mib-1 were obtained by counting the percentage of positive nuclei in $10 \mathrm{HPF}$ and by expressing its value as a percentage.

Immunofluorescence and confocal microscopy. For immunofluorescence assay, 786-O SuR cells (40000 per well) were plated in 12 -well plates, previously covered with a glass cover slide (BD Biosciences, San Jose, CA, USA). Then, cells were treated with NVP-LDE225, everolimus, or sunitinib, alone or with their combinations. After $24 \mathrm{~h}$ of treatment, cells were fixed with freshly prepared $4 \%$ paraformaldehyde in PBS, permeabilised with $0.2 \%$ Triton X-100 for $5 \mathrm{~min}$, and then rinsed three times with $1 \%$ bovine serum albumin in PBS. Cells were then incubated with a primary antibody for $1 \mathrm{~h}$ at room temperature ( $\mathrm{p}$-paxillin, Cell Signaling Technologies), and then with a fluorescently labelled secondary antibody (Cy2-AffiniPure Donkey Anti-Rabbit IgG, LiStarFish, Milan, Italy). Focal adhesion points were evaluated by fluorescent staining of p-paxillin. Phalloidin-FITC $\left(25 \mu \mathrm{g} \mathrm{ml}^{-1}\right)$ was obtained from Sigma-Aldrich (St Louis, MO, USA) and was used to visualise the actin cytoskeleton organisation of 786-O SuR cells. Slides were mounted with 50\% glycerol in PBS and imaged with a Zeiss LSM 510 meta confocal microscope (Zeiss, Oberkochen, Germany) equipped with an oil immersion plan apochromat $\times 63$ objective 1.4 NA. Quantification of focal adhesion points was performed using ImageJ software (US National Institutes of Health NIH, Bethesda, MD, USA).

Statistical analysis. The results of all in vitro experiments were analysed with the Student $t$-test and expressed as means and s.d. for at least three independent experiments performed in triplicate. 
One-way ANOVA and Dunnett's multiple comparison post test determined the statistical significance of tumour growth, whereas the log-rank test determined the statistical significance of mice survival. All reported $P$-values were two-sided. Analyses were done with the BMDP New System statistical package version 1.0 for Microsoft Windows (BMDP Statistical Software, Los Angeles, CA, USA).

\section{RESULTS}

Inhibition of the Hh pathway by NVP-LDE225 potentiates the antiproliferative effects of everolimus and sunitinib in human RCC cell lines. The expression of $\mathrm{Hh}$ transducers has been described in different human cancer cell lines (Heller et al, 2012; Nakamura et al, 2012; Steg et al, 2012). Accordingly, we examined the basal protein expression of Gli-1, Gli-2, and Smo in 786-O and 769-P cells RCC cell lines, both in VHL-mutated cells and in VHL wild-type ACHN cells. Furthermore, the protein expression of all three transducers was also examined in 786-O SuR cells, generated through a validated protocol of in vivo selection (Monteleone et al, 2013). The expression levels of Gli-1, Gli-2, and Smo were similar in all cell lines (Figure 1A). Then to assess the functional role of the Hh pathway, we studied the effects of the Smo inhibitor NVPLDE225 on RCC cell line proliferation. All tested cancer cells were inhibited by the drug in a concentration-dependent manner, with an $\mathrm{IC}_{50}$ ranging between 2 and $3 \mu \mathrm{M}$ (Figure 1B). Indeed, western blot revealed that NVP-LDE225 at a concentration of $5 \mu \mathrm{M}$ not only moderately reduced Gli- 1 expression by $\sim 60 \%$, but also moderately inhibited the activity of two well-known transducers of cell proliferation and survival, Akt and MAPK, by $\sim 40 \%$. Moreover, Gli-2 expression decreased in a concentration-dependent manner (Figure 1C).

We next evaluated the effects of NVP-LDE225 in combination with the mTOR inhibitor everolimus and the VEGFR TKI sunitinib. As shown in Figure 2, single-agent treatment with everolimus or sunitinib was effective against RCC cell lines. In particular, whereas everolimus alone inhibited cell proliferation with $\mathrm{IC}_{50}$ values ranging between 0.1 and $1 \mu \mathrm{M}$ (Figure 2A), sunitinib inhibited cell proliferation with $\mathrm{IC}_{50}$ values ranging between 1.5 and $2.5 \mu \mathrm{M}$ (Figure $2 \mathrm{~B}$ ), as previously demonstrated (Damiano et al, 2013). To test the drugs at their equipotent ratio, we used these data to determine the appropriate concentrations for the combination treatments. Specifically, the combination of NVPLDE225 and everolimus moderately inhibited RCC proliferation. The $\mathrm{IC}_{50}$ doses for this combined treatment were 2.5 and $1 \mu \mathrm{M}$ for NVP-LDE225 and everolimus, respectively (Figure 2A). On the other hand, combination of NVP-LDE225 and sunitinib, compared with everolimus, induced a lower antiproliferative effect at all tested doses. The concentration required for the $\mathrm{IC}_{50}$ was $2 \mu \mathrm{M}$ for both drugs (Figure 2B). Interestingly, the inhibitory effect of such combinations was also observed in resistant 786-O SuR cells. Addition of NVP-LDE225 to everolimus or sunitinib elicited
A
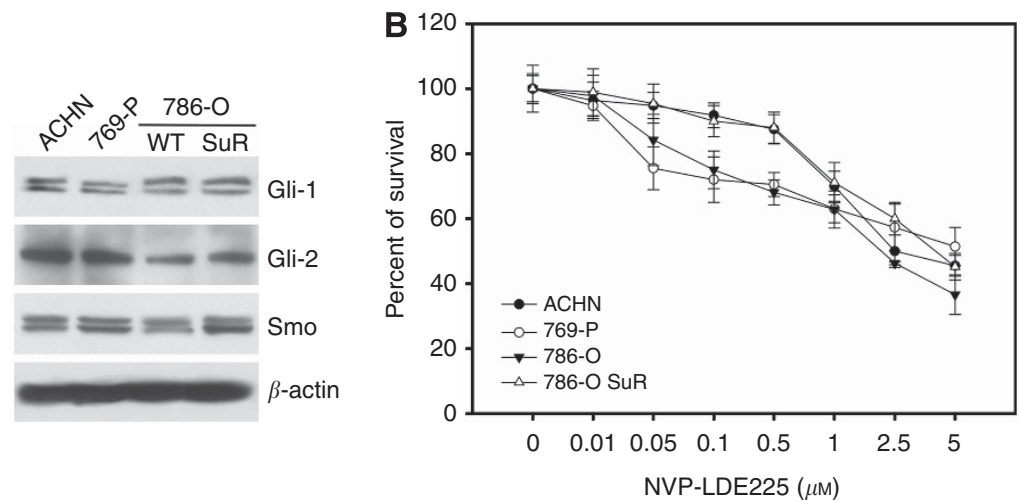

C

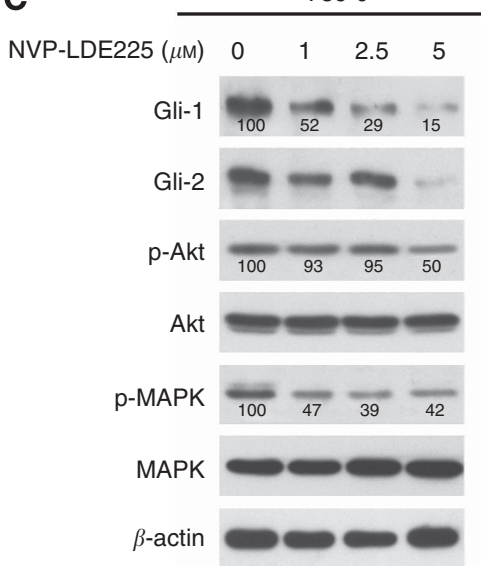

786-0 SuR

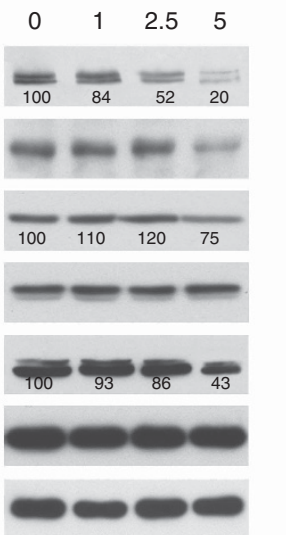

769-P

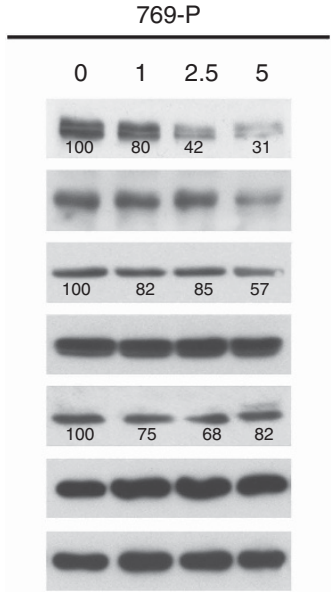

Figure 1. Expression of some of the Hh pathway transducers and the effect of Smo inhibition on human renal cancer cell lines. (A) Western blot analysis on total cell lysates from ACHN, 769-P, 786-O, and 786-O SuR renal cancer cell lines. (B) Percentage of survival of ACHN, 769-P, 786-O, and 786-O SuR renal cancer cell lines treated with NVP-LDE225, as measured by MTT assay. Data represent the mean ( \pm s.d.) of three independent experiments, each performed in triplicate, compared with control (cells treated with DMSO). Error bars indicate s.d. (C) Western blot analysis on total cell lysates from renal cancer cell lines treated with NVP-LDE225 at different concentrations. Densitometric measurements were normalised to $\beta$-actin and reported under western blot images. 
A

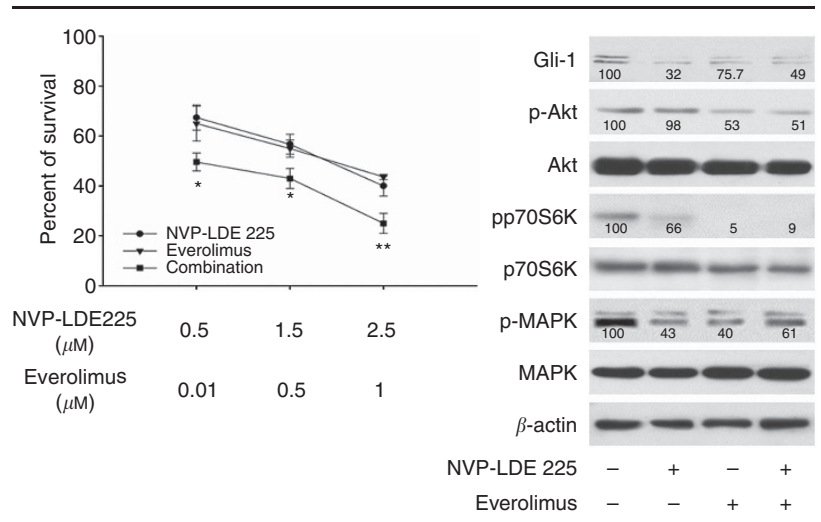

786-0 SuR

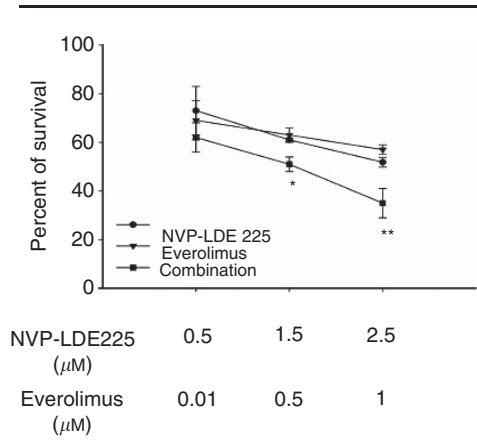

B

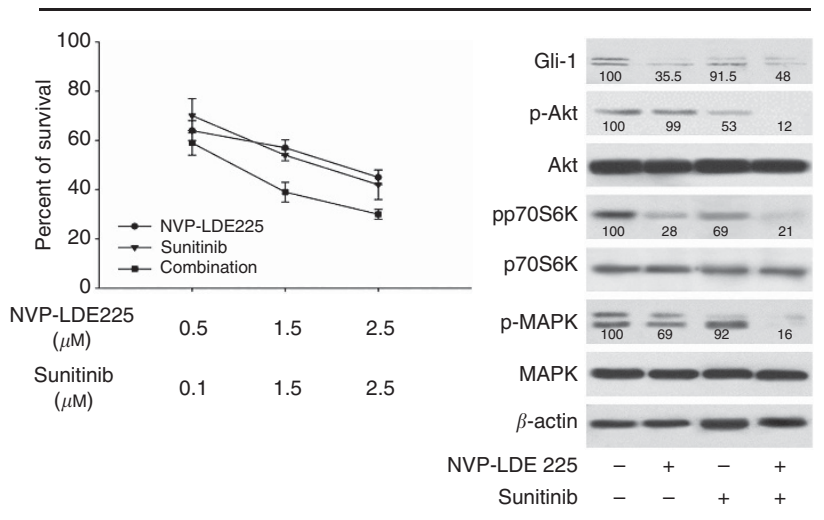

786-0 SuR

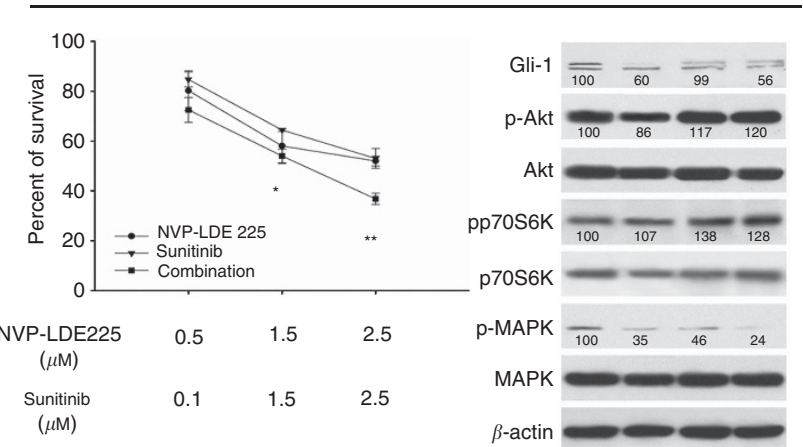

NVP-LDE $225-\quad+\quad-\quad+$

Sunitinib - $\quad+\quad+$

Figure 2. Combination of NVP-LDE225 and everolimus or sunitinib synergistically inhibits survival of human renal cancer cell lines. (A) Percentage of survival of 786-O, 786-O SuR, and 769-P renal cancer cell lines treated with NVP-LDE225 and everolimus or their combination, as measured by the MTT assay. Data represent the mean ( \pm s.d.) of three independent experiments, each performed in triplicate, compared with control (cells treated with DMSO). Western blot analysis on total cell lysates from 786-O, 786-O SuR, and 769-P renal cancer cell lines treated with NVP-LDE225 (2.5 $\mu \mathrm{m})$ and everolimus $(1 \mu \mathrm{m})$ alone or their combination. (B) Percentage of survival of 786-O, 786-O SuR, and 769-P renal cancer cell lines treated with NVP-LDE225 and sunitinib, alone or their combination, as measured by the MTT assay. Data represent the mean ( \pm s.d.) of three independent experiments, each performed in triplicate, compared with control (cells treated with DMSO). Western blot analysis performed on total cell lysates from 786-O, 786-O SuR, and 769-P renal cancer cell lines treated with NVP-LDE225 (2.5 $\mu \mathrm{m})$, sunitinib (1 $\mu \mathrm{M})$, alone or their combination. Error bars indicate s.d. Asterisks indicate statistical significance of combined treatment vs everolimus/sunitinib alone, as determined by Student t-test ( ${ }^{\star} P<0.05$, two-sided; ${ }^{\star} P<<0.005$, two-sided ). Densitometric measurements were normalised to $\beta$-actin and reported under the western blot images.

changes in the expression of some intracellular transducers, as revealed by western blot analysis. Gli-1 expression was decreased in all cell lines, whereas the activity of Akt, p70S6K, and MAPK was reduced by both combination treatments in 786-O and 769-P cells
(Figures 2A and B). In 786-O SuR cells, Akt and p70S6K activation was inhibited by the combination of NVP-LDE225 and everolimus, but not by the combination of NVP-LDE225 and sunitinib. However, a statistically significant reduction in MAPK activation 
was observed when the $\mathrm{Hh}$ inhibitor was added to either everolimus or sunitinib (Figures $2 \mathrm{~A}$ and $\mathrm{B}$ ).

To better evaluate the antiproliferative effect of the interaction between NVP-LDE225 and the two drugs, we measured the combination index (CI) (Chou and Talalay, 1984) using an automated calculation software. Based on this mathematical model, the combination is considered synergistic when the $\mathrm{CI}<1.0$ and is highly synergistic when the $\mathrm{CI}<0.5$. Remarkably, NVP-LDE225 combined with everolimus or sunitinib synergistically produced an antitumour action in all cell lines (Supplementary Table 1 and Supplementary Figure S1A and S1B).

In addition, we investigated the direct role of Gli-1/2 inhibition in RCC tumour growth. To this aim, instead of examining the indirect effect of NVP-LDE225 on Gli-1 modulation, we studied the antiproliferative activity of another selective inhibitor, namely GANT-61, a small molecule able to specifically inhibit both Gli-1 and Gli-2 (Supplementary Figure S2A). We found that GANT-61 had almost no effect on the proliferation of all cell lines tested, requiring an $\mathrm{IC}_{50}$ of up to $25 \mu \mathrm{M}$, a concentration likely associated with cytotoxicity. Even when combined with everolimus or sunitinib, GANT-61 induced no changes in proliferation compared with single-agent treatments (Supplementary Figure S2B), thereby suggesting that upstream Smo-dependent inhibition of the $\mathrm{Hh}$ pathway is more efficient than selective Gli inhibition.
NVP-LDE225 cooperates with everolimus and sunitinib to inhibit migration and invasion of RCC cells. As activated Hh might enhance tumour invasiveness rather than proliferation (Inaguma et al, 2011; Cao et al, 2012), we evaluated the effect of NVP-LDE225, everolimus, and sunitinib alone or in combination on cell migration and invasion capabilities. To this aim, we carried out wound-healing and fibroblasts monolayer invasion assays, respectively. As depicted in Figure 3A, which shows the woundhealing closure percentages between untreated and treated cells, the combination of NVP-LDE225 and everolimus was more effective than single drug treatments $(P$-values reported in Supplementary Table 2A). Similarly, the combination of NVPLDE225 and sunitinib was also effective in inhibiting the migration capability of RCC cells, albeit to a lower extent than everolimus $(P$-values reported in Supplementary Table $2 \mathrm{~B})$. Interestingly, when the resistant 786-O SuR cell line was treated with NVPLDE225, they were significantly resensitised to sunitinib ( $P$-values reported in Supplementary Table 2C). Representative pictures of scratches on cell cultures with and without treatments, at different time point $(0$ and $24 \mathrm{~h})$ are depicted in Supplementary Figure S3A.

The analysis of tumour cell invasion also demonstrated some relevant changes induced by the drug combinations, as shown in Figure $3 \mathrm{~B}$, which reports the percentage of invasion of a human fibroblast monolayer by tumour cells. In particular, we found that
A

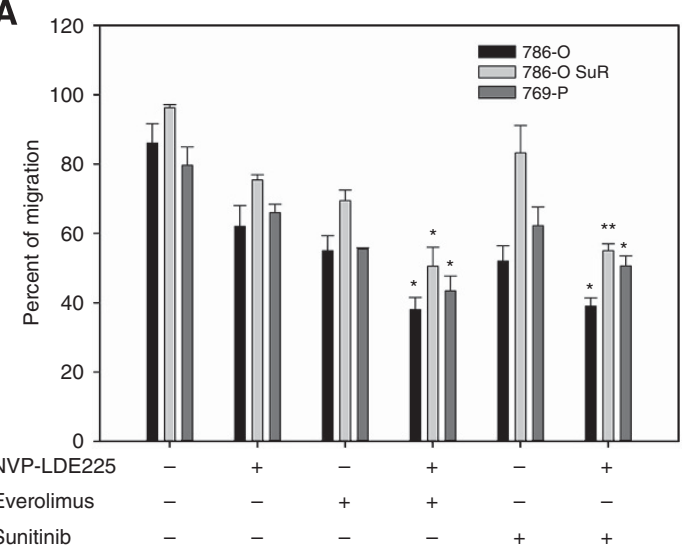

B

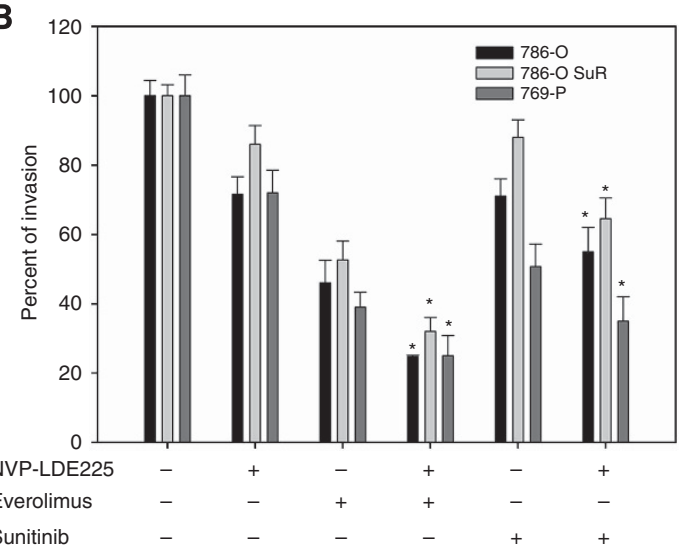

C

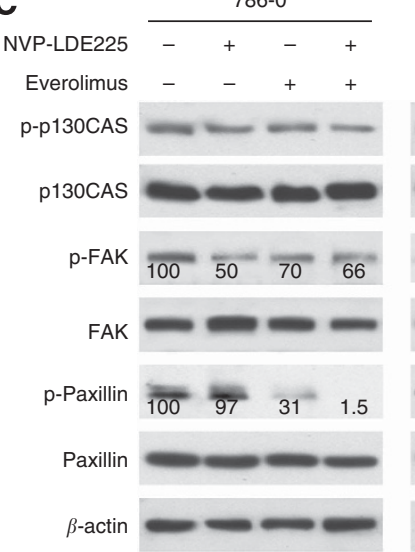

D

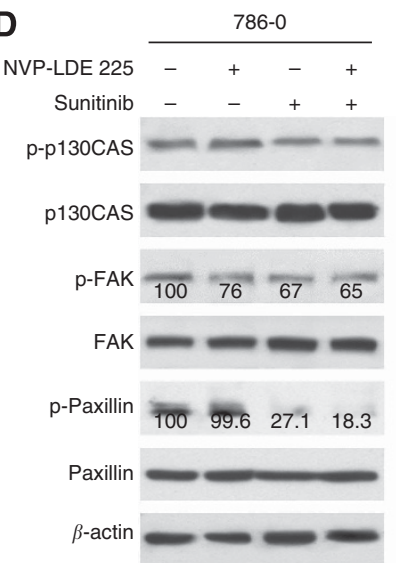

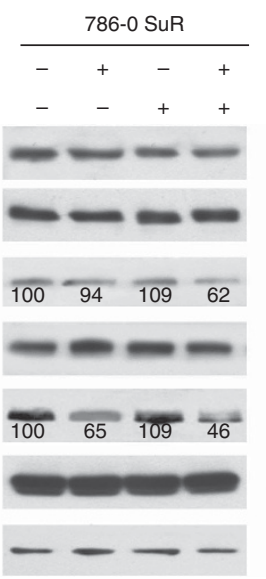
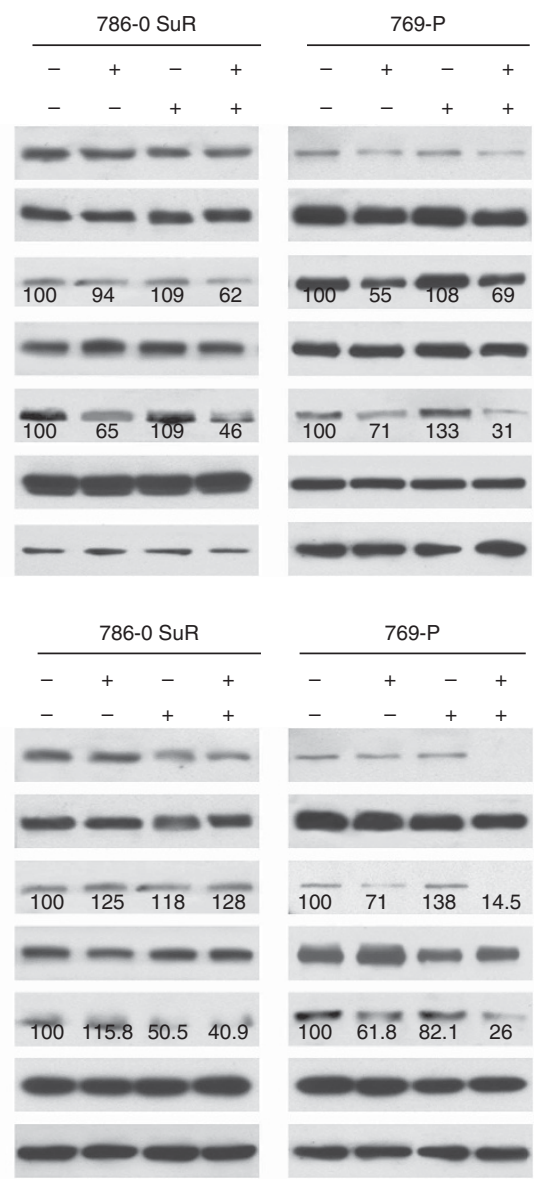

Figure 3. Combination of NVP-LDE225 with everolimus and/or sunitinib efficiently blocks migration and invasion of human renal cancer cell lines. (A) Percentage of migration of 786-O, 786-O SuR, and 769-P human renal cancer cell lines, as measured by wound-healing assay. (B) Percentage of invasion of 786-O, 786-O SuR, and 769-P human renal cancer cell lines, as measured by fibroblasts monolayer invasion assay. Data represent the mean ( \pm s.d.) of three independent experiments, each performed in triplicate, as compared to control (cells treated with DMSO). Error bars indicate s.d. Asterisks indicate statistical significance of combined treatment vs everolimus/sunitinib alone, as determined by the Student t-test ( ${ }^{*}<0.05$, two-sided; ${ }^{* \star} P<0.005$, two-sided). (C, D) Western blot analysis of total cell lysates from 786-O, 786-O SuR, and 769-P human renal cancer cell lines treated with NVP-LDE225 $(2.5 \mu \mathrm{M})$, everolimus $(1 \mu \mathrm{M})$, and their combination or with NVP-LDE225 $(2.5 \mu \mathrm{M})$, sunitinib $(1 \mu \mathrm{M})$, and their combinations. Densitometric measurements were normalised to $\beta$-actin and reported under western blot images. 
although both combinations, that is, NVP-LDE225 plus everolimus or sunitinib, effectively inhibited tumour cell invasion capability, everolimus plus NVP-LDE225 had a major effect ( $P$-values reported in Supplementary Table 2A-C). In Supplementary Figure S3B, we depict representative drops of RCC cells/matrigel with and without treatments with NVP-LDE225, everolimus, sunitinib, or their combination, at different time point.

Besides inhibiting tumour cell invasion, addition of NVPLDE225 to everolimus or sunitinib also reduced the expression of the phosphorylated/activated forms of proteins involved in cell migration/invasion, including FAK and paxillin, which displayed variable entity among the different cell lines tested (Figures $3 \mathrm{C}$ and D).

Actin cytoskeleton organisation of 786-O SuR cells was analysed by confocal microscopy. Actin-based structures were revealed by phalloidin, whereas localisation of focal adhesion points was achieved by fluorescent staining of p-paxillin. $\beta$-actin and p-paxillin were well organised in untreated cells; instead, the single-agent treatments were able to mildly disassemble cytoskeleton organisation and focal adhesion points formation.
These effects were much more evident with the combination treatments (Figure 4 and Supplementary Figure S4).

NVP-LDE225 treatment potentiates antitumour activity of everolimus and sunitinib in RCC xenografts. As paracrine activation of $\mathrm{Hh}$ signalling in the tumour microenvironment provides a more favourable environment for tumour cellular proliferation, metastasis, and resistance to anticancer therapies (Das et al, 2013), we studied the effect of NVP-LDE225 combined with everolimus or sunitinib in Balb/c nude mice s.c. xenografted with 786-O SuR cells. In vivo administration of NVP-LDE225 combined with everolimus synergistically induced tumour growth inhibition (Figure 5A). In particular, untreated mice reached the maximum allowed tumour size, ca. $2 \mathrm{~cm}^{3}$, on day 49 , only 2 weeks after the end of the treatment. At this time point, instead, NVP-LDE225 and everolimus produced $41 \%$ and $60 \%$ of growth inhibition, respectively. An even more potent effect was, however, observed in the group of mice treated with the combination of the two drugs, exhibiting $70 \%$ of tumour growth

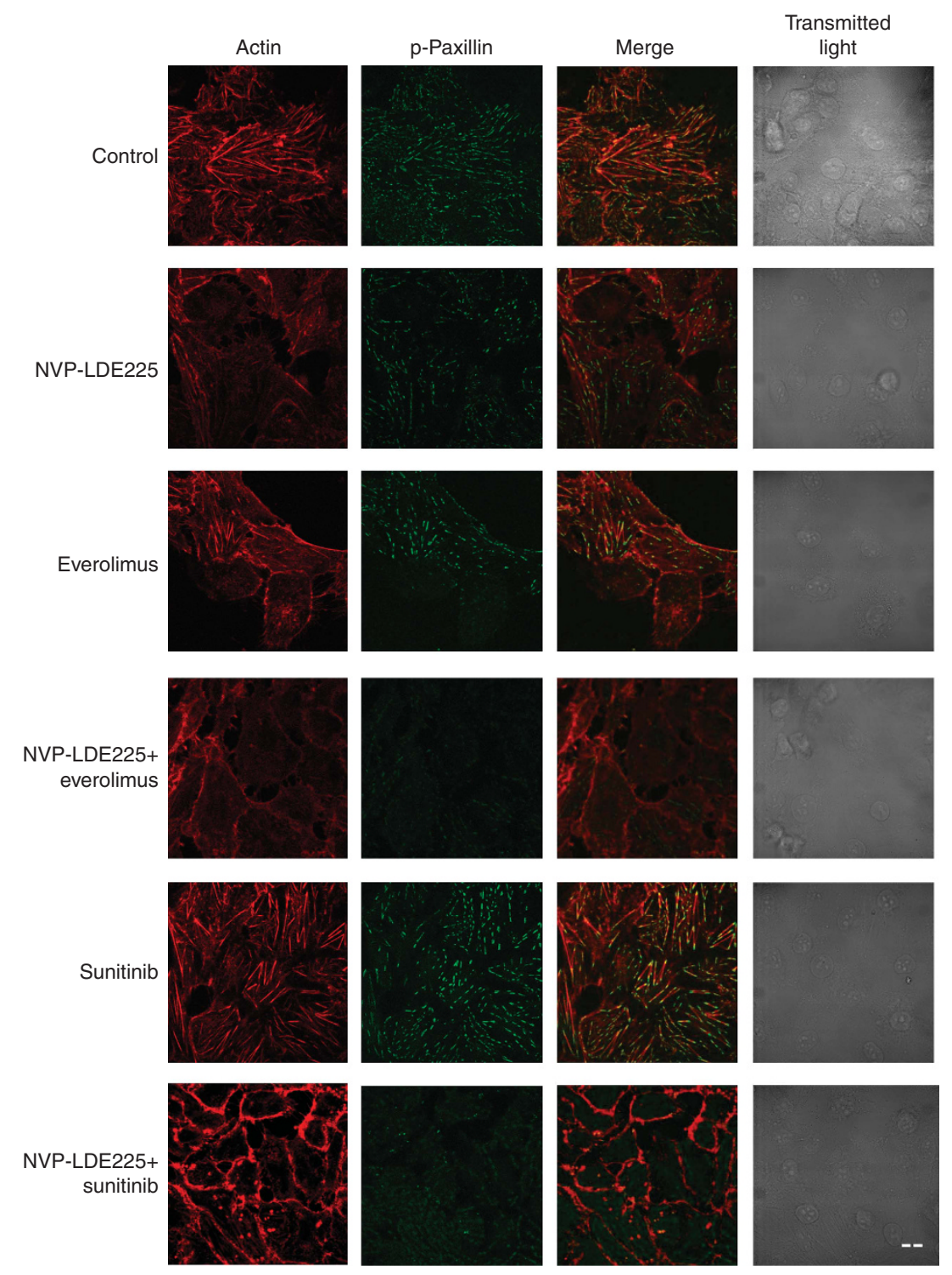

Figure 4. NVP-LDE225, everolimus, sunitinib, and their combination interfere with actin and with intracellular organisation of focal adhesion points. Cytoskeleton organisation of 786-O SuR treated with NVP-LDE225 $(2.5 \mu \mathrm{M})$, everolimus $(1 \mu \mathrm{M})$, sunitinib $(1 \mu \mathrm{M})$, and their combination for $24 \mathrm{~h}$ was analysed by confocal microscopy. Actin-based structures were revealed by rhodaminated phalloidin staining (red fluorescence). Localisation of focal adhesion points was obtained by immunofluorescent staining of p-paxillin (green fluorescence). Merged row images show overlapping of p-paxillin and actin signals. Moreover, all captures were shown in transmitted light. Scale bars, $10 \mu \mathrm{m}$. 
A

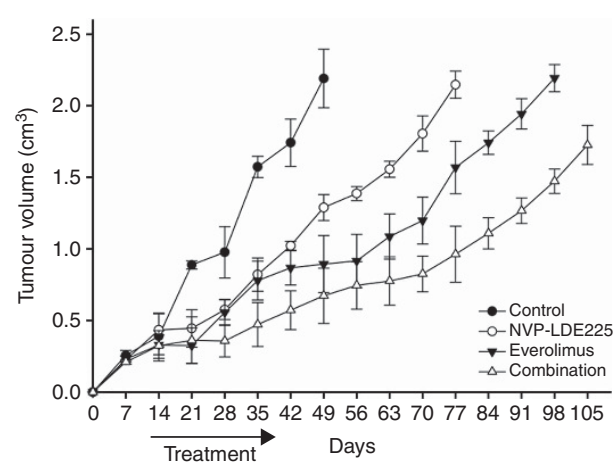

D

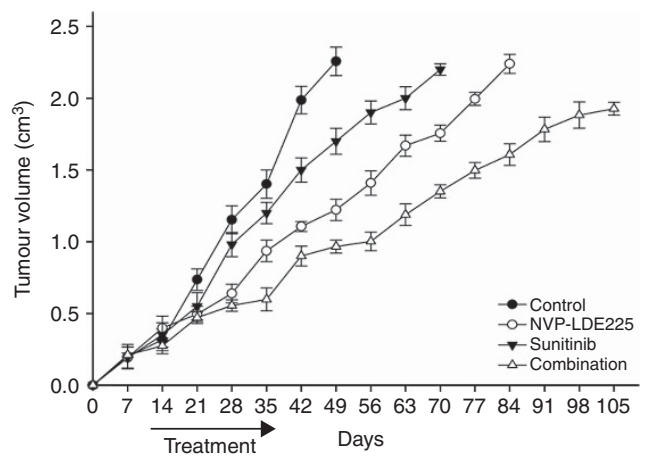

B

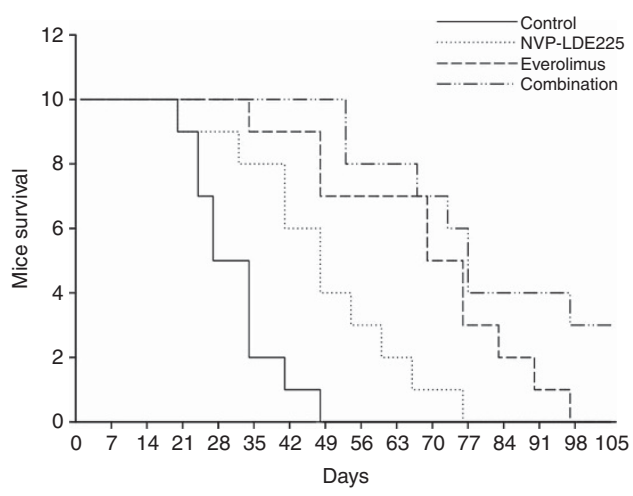

E

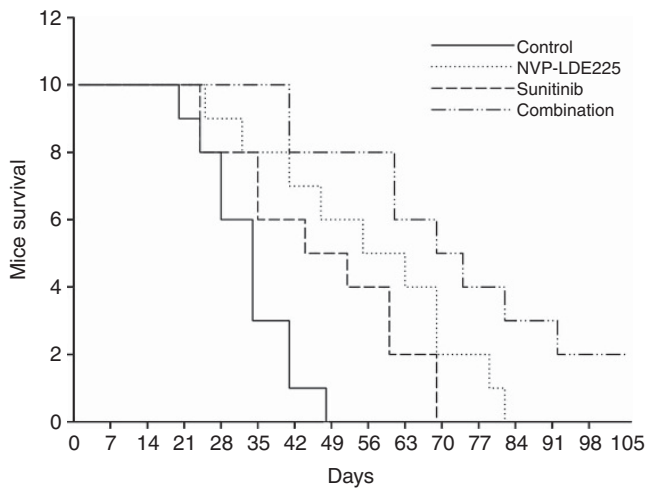

C

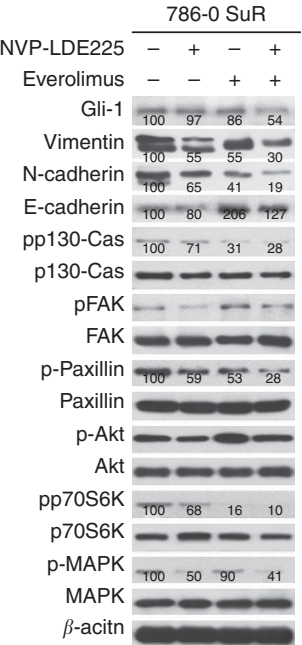

$\mathbf{F}$

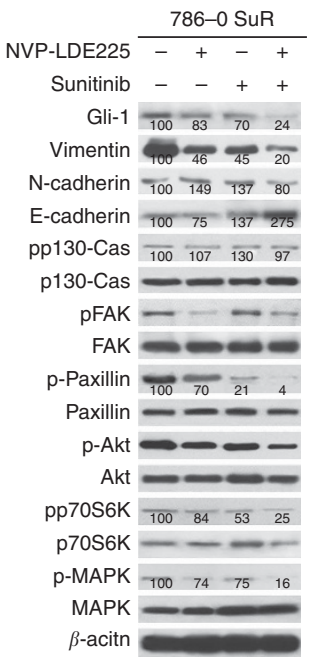

Figure 5. Combination of NVP-LDE225 and everolimus/sunitinib induces a cooperative antitumour effect in 786-O SuR tumour xenografts. (A-D) After 14 days following injection of 786-O SuR cells, mice were randomised (10 per group) to receive one daily administrations of NVP-LDE225, everolimus, sunitinib, or their combination for 3 weeks (as described in Materials and Methods section). The one-way ANOVA test was used to compare tumour sizes between the different treatment groups with respect to the median survival of the control group (24.5 days). The results were statistically significant for the combination treatment as opposed to single agents $(P<0.001)$. (B-E) Median survival was statistically significant for the combinations vs control $(P<0.001)$, as evaluated by long-rank test. $(\mathbf{C}-\mathbf{F})$ Western blot analysis on total lysates from 786-O SuR tumour specimens of two mice per group killed on day 35. Densitometric measurements were normalised to $\beta$-actin and reported under western blot images.

inhibition. NVP-LDE225-treated mice reached the tumour size of $2 \mathrm{~cm}^{3}$ on day 77, 6 weeks after the end of the treatment, whereas everolimus-treated mice reached the same tumour size slightly later, that is, on day 98, 9 weeks after the end of the treatment. Noticeably, the combination of NVP-LDE225 and everolimus caused a potent and long-lasting cooperative antitumour activity, maintaining the tumour size at $1.72 \mathrm{~cm}^{3}$ throughout the experiment. One-way ANOVA revealed that the differences in tumour size were statistically significant in all the treatment groups (combination $v s$ single agents, $P<0.001$ at the median survival of the control group; Figure 5A). Consistently, mice treated with the combined therapy showed a statistically significant prolonged median survival compared with control mice (combination vs control, median survival 78 vs 31.50 days, hazard ratio $=0.03732$, $95 \% \mathrm{CI}=0.009228-0.1509, P<0.0001$; Figure $5 \mathrm{~B})$. Equally important, no significant signs of toxicity were observed in the combination group compared with single-agent treatments.

Western blot analysis done on tumours removed at the end of treatment (day 35) revealed that the combination of NVP-LDE225 and everolimus reduced by $\sim 50 \%$ the expression of Gli-1, a target gene of the Hh inhibitor. Although this combination only mildly reduced pAkt levels, it exhibited a much stronger inhibitory effect on p70S6K, MAPK, and paxillin $(90 \%, 60 \%$, and $70 \%$, respectively). Interestingly, this combined treatment was also able to increase E-cadherin, and to decrease both vimentin and $\mathrm{N}$-cadherin expression levels (Figure 5C). In effect, these protein markers are known to induce EMT, a process by which epithelial cells lose their cell polarity and cell-cell adhesion, and gain migratory and invasive properties, thereby becoming mesenchymal stem cells.

The in vivo antitumour activity of NVP-LDE225 combined with sunitinib is reported in Figure 5D. As expected, in 786-O SuR xenografts, sunitinib had a modest effect, with a $35 \%$ tumour growth inhibition. A more potent activity was observed in the group treated with the combination treatments, as evidenced by an overall $57 \%$ tumour growth inhibition. In effect, mice treated with the single agents exhibited only mild changes in tumour size, as opposed to the combined treatments. For instance, the tumour size of sunitinib-treated mice reached the size of $2 \mathrm{~cm}^{3}$ on day 70,5 weeks after the end of the treatment. 
Similarly, NVP-LDE225-treated mice reached this same tumour size slightly later, on day 84,7 weeks after the end of the treatment. By contrast, NVP-LDE225 in combination with sunitinib caused a potent and long-lasting cooperative antitumour activity, maintaining the tumour size at $1.92 \mathrm{~cm}^{3}$ until the end of the experiment. Thus, as revealed by one-way ANOVA, differences in tumour size were statistically significant in all treatment groups (combination vs single agents, $P=0.003$ at the median survival of the control group; Figure 5D). Consistently, mice treated with the combination therapy showed a statistically significant prolonged median survival compared with control mice (combination vs control, median survival 72.5 vs 35 days, hazard ratio $=0.06644,95 \%$ $\mathrm{CI}=0.01775-0.2487, \quad P<0.0001 ;$ Figure 5E). Moreover, the combined treatments were well tolerated, as no weight loss or other signs of acute or delayed toxicity were observed after treatment.

Western blot analysis done on tumours removed at the end of treatment (day 35) revealed that NVP-LDE225 combined with sunitinib was also effective in reducing the expression of Gli-1, a direct target of the $\mathrm{Hh}$ inhibitor $(\sim 70 \%)$. Furthermore this combined treatment was also able to mildly reduce pAkt levels. However, it had a much more evident inhibitory effect on the activated forms of p70S6K, MAPK, and paxillin (75\%, 80\% and $90 \%$, respectively). Interestingly, changes in the expression levels of the markers involved in EMT were also observed. Indeed, following the combined treatment, E-cadherin increased, and vimentin and $\mathrm{N}$-cadherin decreased (Figure 5F). Furthermore, immunohistochemical staining of tumours demonstrated that, in addition to vimentin, CD31 (a marker of angiogenesis) and Mib-1 (a proliferation marker) expression levels were also reduced by the combination treatments. In particular, in untreated tumours, staining for vimentin produced a total score of 300 (strong $3+$ in $100 \%$ of tumour cells), whereas tumours treated with the combined treatments yielded a total score of 80 (weak $1+$ in $80 \%$ of tumour cells) and 75 (weak $1+$ in $75 \%$ of tumour cells), respectively. Similarly, CD31 and Mib-1 expressions were decreased by both types of combined treatments (Supplementary Figure S5).

A
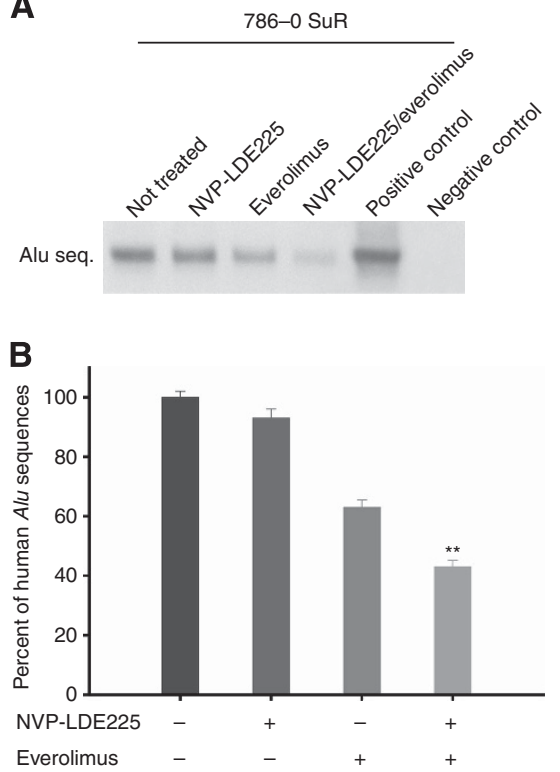

As expected, combination of NVP-LDE225 with everolimus, but not sunitinib, was effective in reducing hVEGF levels in tumour lysates obtained from 786-O SuR (Supplementary Figure S6).

Combination with NVP-LDE225 and everolimus or sunitinib inhibits distant metastases formation. As our in vivo studies revealed expression changes of E-cadherin, vimentin, and N-cadherin on tumour samples derived from mice treated with the combination of NVP-LDE225 and everolimus or sunitinib (Figures $5 \mathrm{C}-\mathrm{F}$ ), we also investigated whether the combination therapies could block tumour metastatic behaviour. Therefore, we performed an artificial metastasis assay by injecting 786-O SuR cells into the tail vein of Balb/c nude mice (six mice per group), and then treated them with NVP-LDE225, everolimus, or sunitinib alone or in combination. To measure lung micrometastasis formation, we quantified the portion of human DNA in mouse lungs using real-time PCR for human Alu sequences, as previously described (Schneider et al, 2002). Untreated mice showed a detectable amount of human DNA in their lungs. No other site of distant metastases were observed in other organs (liver, spleen, brain, and bone). As expected, the combination of NVP-LDE225 with either everolimus or sunitinib was much more effective than single drugs in reducing levels of human DNA in mouse lungs (Figures 6A-C). Similarly, densitometric analysis on PCR bands further confirmed the effectiveness of the combination therapies even in blocking micrometastasis formation: NVP-LDE225 plus everolimus yielded a 60\% inhibition, whereas NVP-LDE225 plus sunitinib yielded a 50\% inhibition (Figures 6B-D). By contrast, single administrations of everolimus and sunitinib inhibited micrometastasis formation by $40 \%$ and $30 \%$, respectively.

\section{DISCUSSION}

Renal cell carcinoma is a highly vascularised tumour in which angiogenesis is mediated by numerous proangiogenic factors. Conceivably, one of the major molecular pathways involved in

C
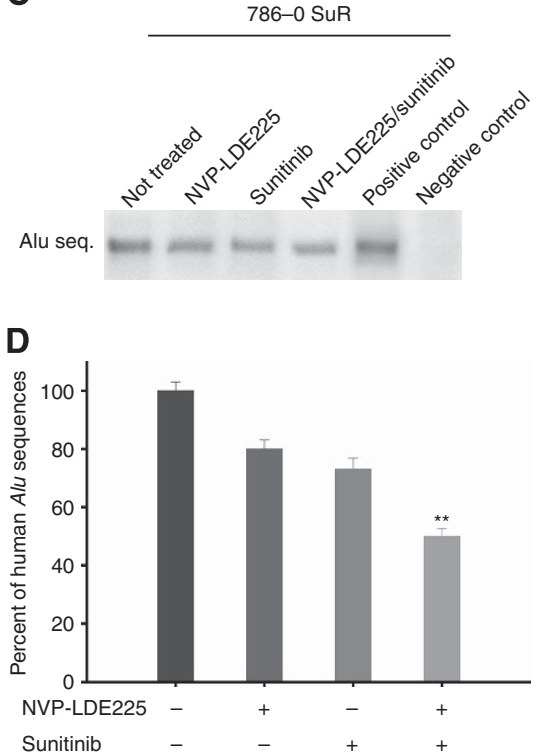

Figure 6. Combination of NVP-LDE225 and everolimus or sunitinib inhibits distant metastasis formation. (A-C) PCR of DNA extracted from lungs of mice after tail vein injection of 786-O SuR cells. (B-D) Percentage of human Alu sequences in the lungs of mice after tail vein injection with 786-O SuR cells and treatment with NVP-LDE225, everolimus, sunitinib, or their combination, as described in the Materials and Methods section. Data were calculated with mean cycle threshold (CT) values, normalised for positive control. Data represent the mean ( \pm s.d.) of three independent experiments, each performed in triplicate, as compared to single agent. Error bars indicate s.d. Asterisks indicate statistical significance of combined treatment vs everolimus alone, as determined by the Student $t$-test ( ${ }^{\star \star} P<0.005$, two-sided). 
RCC pathogenesis is the Hh signalling pathway. In effect, this pathway is critical to normal kidney development, as it regulates the proliferation and differentiation of mesenchymal cells in the metanephric kidney ( $\mathrm{Yu}$ et al, 2002). In addition, $\mathrm{Hh}$ is also involved in embryonic vasculogenesis and vascular remodelling (Charron et al, 2003; Vokes et al, 2004). However, in cancer pathogenesis, it elicits tumour growth by interfering with both cancer cells and their microenvironment. Recently, small-molecule inhibitors of $\mathrm{Hh}$ signalling have been synthesised for cancer treatment, and the Hh pathway inhibitor vismodegib has been approved for patients with advanced BCC. However, this class of compounds has failed to show significant clinical activity in other solid tumours (McMillan and Matsui, 2012), probably because multiple pathways are deregulated in cancerous cells.

In the present study, we evaluated the effects of the $\mathrm{Hh}$ signalling pathway inhibitor NVP-LDE225 on the growth and invasion of human RCC cells, both in vitro and in vivo. We also analysed whether NVP-LDE225 in combination with sunitinib or everolimus could serve as a therapeutic strategy potentially able to overcome RCC resistance to sunitinib. We demonstrated that Hh pharmacological inhibition cooperates with either everolimus or sunitinib in inhibiting proliferation, migration, and invasion of RCC cells. Evidence for the synergistic inhibitory action of these agents on tumour growth was supported by the reduced activation of proteins involved in cell proliferation and motility observed after the combination treatments. In particular, whereas NVP-LDE225 plus everolimus was more effective in reducing the expression of pAkt and pp70S6K in the 786-O SuR cell line, NVP-LDE225 plus sunitinib was effective only in reducing the expression of the activated form of MAPK. Moreover, whereas in 786-O SuR sunitinib alone was totally ineffective in inhibiting cell migration and invasion, both combinations markedly inhibited cell migration and invasion. In parallel, a reduction in the activity of transducers involved in migration/invasion pathways, such as p130Cas, FAK, and paxillin, was also observed after combination treatments (Figure 3). These results are corroborated by previous studies describing the crosstalk between $\mathrm{Hh}$ and other signalling pathways in many tumour types (Brechbiel et al, 2014). In pancreatic cancer, for instance, the combination of cyclopamine and the mTOR inhibitor rapamycin reduces the number of tumorigenic cancer stem cells, both in vitro and in vivo, whereas the administration of single agents does not (Mueller et al, 2009). Moreover, compelling recent evidence has reported that in PTEN-deficient glioblastomas, Shh and PI3K pathways synergize to promote tumour growth and viability, and targeting both pathways through the combination of NVP-LDE225 and the PI3K inhibitor buparlisib dramatically arrests tumour growth (Gruber Filbin et al, 2013).

Our data suggest that acquired resistance to the VEGFR TKI sunitinib can be reversed by the combination of NVP-LDE225 with either sunitinib or everolimus, as confirmed by in vivo experiments. When 786-O SuR cells were xenografted in nude mice, they maintained a certain degree of sensitivity to sunitinib (Figures 5C and $\mathrm{D}$ ). This finding is consistent with other reports demonstrating that acquired resistance to VEGFR antagonists might, at least in part, be mediated by reversible changes. Indeed, studies have shown that tumours can restore their sensitivity to VEGF blockade after reimplantation in a naive host, and that $75 \%$ of genes, whose expression is altered upon resistance, appear to revert to baseline when tumours are reimplanted into mice (Huang et al, 2010a,b; Zhang et al, 2011). This event, besides highlighting the importance of the tumour microenvironment in mediating the inhibitory effect of TKIs against VEGFRs, further substantiate our finding on the putative role of $\mathrm{Hh}$ signalling in supporting the resistant phenotype in vivo. In our RCC models, combination of NVP-LDE225 with either everolimus or sunitinib had a potent antitumour effect on human renal cancer xenografts, as evidenced by the strong inhibition of tumour growth, prolongation of mice survival, and interference with signal transduction. We also demonstrated that these effects were associated with induction of E-cadherin expression and reduction in vimentin and $\mathrm{N}$-cadherin. A possible explanation for this finding is that initiation of metastasis requires invasion, which is enabled by EMT (Gao et al, 2012). More specifically, carcinoma cells in primary tumour lose cell-cell adhesion mediated by E-cadherin repression, break through the basement membrane with increased invasive properties, and enter the bloodstream through intravasation (Chaffer and Weinberg, 2011; Leccia et al, 2012). In human non small-cell lung cancer cell lines, the induction of EMT by chronic exposure to TGF- $\beta 1$ leads to the upregulation of Shh at both mRNA and protein levels, causing activation of Hh signalling. This process can though be attenuated by knockdown of Shh by siRNA or by the use of specific $\mathrm{Hh}$ inhibitors, as confirmed by the induction of the epithelial marker E-cadherin (Maitah et al, 2011). Consistently, our data suggest that the combined treatment of NVP-LDE225 and everolimus or sunitinib could interfere with the EMT process and distant metastatic spread. Indeed, combined treatments, especially with everolimus, not only significantly modulated EMT markers, as measured by IHC and WB analyses, but also reduced the formation of lung micrometastases in nude mice.

In conclusion, we have demonstrated that NVP-LDE225 combined with either everolimus or sunitinib is highly effective in inhibiting and delaying tumour growth, even in SuR cells. Mice treated with the combination treatment showed a statistically significant reduction in tumour growth that lasted weeks after the end of the combined treatment. Moreover, the combination treatments prolonged median survival among mice, as opposed to mice treated with single treatments or control. Overall, this study indicates that the pharmacological inhibition of aberrant $\mathrm{Hh}$ signalling could be integrated with current treatments for human RCC. Finally, our results warrant further studies to test novel and promising therapeutic approaches based on the combination of NVP-LDE225 and other targeted agents for RCC patients, including those resistant to sunitinib.

\section{ACKNOWLEDGEMENTS}

This study was supported in part by Associazione Italiana per la Ricerca sul Cancro My First Grant 2011-2014 (MFAG-11473) to RB, by the F.A.R.O. project 2011 to RB, by Ministero della Salute, Ministero dell'Università e della Ricerca (PRIN 2010NFEB9L), and by Regione Campania POR Campania FSE 2007-2013, Project CREME (Campania Research in Experimental Medicine). Dr. Paola Merolla - freelance stylistic editor of scientific manuscripts for ESL authors and course coordinator, and instructor of Manuscript Writing for Non-Native English Speakers, School of Molecular Medicine (Naples, Italy) - edited and revised the text for language and clarity.

\section{CONFLICT OF INTEREST}

The authors declare no conflict of interest.

\section{REFERENCES}

Amato RJ (2005) Renal cell carcinoma: review of novel single-agent therapeutics and combination regimens. Ann Oncol 16: 7-15.

Barthélémy P, Hoch B, Chevreau C, Joly F, Laguerre B, Lokiec F, Duclos B (2013) mTOR inhibitors in advanced renal cell carcinomas: From biology to clinical practice. Crit Rev Oncol Hematol 88(1): 42-56.

Behnsawy HM, Shigemura K, Meligy FY, Yamamichi F, Yamashita M, Haung WC, Li X, Miyake H, Tanaka K, Kawabata M, Shirakawa T, 
Fujisawa M (2013) Possible role of sonic hedgehog and epithelialmesenchymal transition in renal cell cancer progression. Korean J Urol 54(8): 547-554.

Brechbiel J, Miller-Moslin K, Adjei AA (2014) Crosstalk between hedgehog and other signaling pathways as a basis for combination therapies in cancer. Cancer Treat Rev 40(6): 750-759S0305-7372(14)00023-1.

Cao X, Geradts J, Dewhirst MW, Lo HW (2012) Upregulation of VEGF-A and CD24 gene expression by the tGLI1 transcription factor contributes to the aggressive behavior of breast cancer cells. Oncogene 31(1): 104-115.

Cao Y, Wang L, Nandy D, Zhang Y, Basu A, Radisky D, Mukhopadhyay D (2008) Neuropilin-1 upholds dedifferentiation and propagation phenotypes of Renal Cell Carcinoma cells by activating Akt and Sonic Hedgehog axes. Cancer Res 68(21): 8667-8672.

Chaffer CL, Weinberg RA (2011) A perspective on cancer cell metastasis. Science 331(6024): 1559-1564.

Chari NS, McDonnell TJ (2007) The sonic hedgehog signaling network in development and neoplasia. Adv Anat Pathol. 14(5): 344-352.

Charron F, Stein E, Jeong J, McMahon AP, Tessier-Lavigne M (2003) The morphogen sonic hedgehog is an axonal chemoattractant that collaborates with netrin-1 in midline axon guidance. Cell 113(1): 11-23.

Chou TC, Talalay P (1984) Quantitative analysis of dose-effect relationships: the combined effects of multiple drugs or enzyme inhibitors. Adv Enzyme Regul 22: 27-55.

Damiano V, Rosa R, Formisano L, Nappi L, Gelardi T, Marciano R, Cozzolino I, Troncone G, Agrawal S, Veneziani BM, De Placido S, Bianco R, Tortora G (2013) Toll-like receptor 9 agonist IMO cooperates with everolimus in renal cell carcinoma by interfering with tumour growth and angiogenesis. Br J Cancer 108(8): 1616-1623.

Das S, Samant RS, Shevde LA (2013) Nonclassical activation of Hedgehog signaling enhances multidrug resistance and makes cancer cells refractory to Smoothened-targeting Hedgehog inhibition. J Biol Chem 288(17): 11824-11833.

Dormoy V, Danilin S, Lindner V, Thomas L, Rothhut S, Coquard C, Helwig JJ, Jacqmin D, Lang H, Massfelder T (2009) The sonic hedgehog signaling pathway is reactivated in human renal cell carcinoma and plays orchestral role in tumor growth. Mol Cancer 8: 123.

Errico M, Riccioni T, Iyer S, Pisano C, Acharya KR, Persico MG, De Falco S (2004) Identification of placenta growth factor determinants for binding and activation of Flt-1 receptor. J Biol Chem 279(42): 43929-43939.

Fellner C (2012) Vismodegib (Erivedge) for advanced basal cell carcinoma. P T 37(12): 670-682.

Fendrich V, Wiese D, Waldmann J, Lauth M, Heverhagen AE, Rehm J, Bartsch DK (2011) Hedgehog inhibition with the orally bioavailable Smo antagonist LDE225 represses tumor growth and prolongs survival in a transgenic mouse model of islet cell neoplasms. Ann Surg 254: 818-823; discussion 823.

Finley DS, Pantuck AJ, Belldegrun AS (2011) Tumor biology and prognostic factors in renal cell carcinoma. Oncologist 16(Suppl 2): 4-13.

Gao D, Vahdat LT, Wong S, Chang JC, Mittal V (2012) Microenvironmental regulation of epithelial-mesenchymal transitions in cancer. Cancer Res. 72(19): 4883-4889.

Gruber Filbin M, Dabral SK, Pazyra-Murphy MF, Ramkissoon S, Kung AL, Pak E, Chung J, Theisen MA, Sun Y, Franchetti Y, Sun Y, Shulman DS, Redjal N, Tabak B, Beroukhim R, Wang Q, Zhao J, Dorsch M, Buonamici S, Ligon KL, Kelleher JF, Segal RA (2013) Coordinate activation of Shh and PI3K signaling in PTEN-deficient glioblastoma: new therapeutic opportunities. Nat Med 19(11): 1518-1523.

Han ME, Lee YS, Baek SY, Kim BS, Kim JB, Oh SO (2009) Hedgehog signaling regulates the survival of gastric cancer cells by regulating the expression of bcl-2. Int J Mol Sci 10(7): 3033-3043.

Heller E, Hurchla MA, Xiang J, Su X, Chen S, Schneider J, Joeng KS, Vidal M, Goldberg L, Deng H, Hornick MC, Prior JL, Piwnica-Worms D, Long F, Cagan R, Weilbaecher KN (2012) Hedgehog signaling inhibition blocks growth of resistant tumors through effects on tumor microenvironment. Cancer Res 72(4): 897-907.

Huang D, Ding Y, Li Y, Luo WM, Zhang ZF, Snider J, Vandenbeldt K, Qian CN, Teh BT (2010a) Sunitinib acts primarily on tumor endothelium rather than tumor cells to inhibit the growth of renal cell carcinoma. Cancer Res 70(3): 1053-1062.

Huang D, Ding Y, Zhou M, Rini BI, Petillo D, Qian CN, Kahnoski R, Futreal PA, Furge KA, Teh BT (2010b) Interleukin-8 mediates resistance to antiangiogenic agent sunitinib in renal cell carcinoma. Cancer Res 70(3): 1063-1071.
Inaguma S, Kasai K, Ikeda H (2011) GLI1 facilitates the migration and invasion of pancreatic cancer cells through MUC5AC-mediated attenuation of E-cadherin. Oncogene 30(6): 714-723.

Leccia F, Nardone A, Corvigno S, Vecchio LD, De Placido S, Salvatore F, Veneziani BM (2012) Cytometric and biochemical characterization of human breast cancer cells reveals heterogeneous myoepithelial phenotypes. Cytometry A 81(11): 960-972.

Lipinski RJ, Hutson PR, Hannam PW, Nydza RJ, Washington IM, Moore RW, Girdaukas GG, Peterson RE, Bushman W (2008) Dose- and routedependent teratogenicity, toxicity, and pharmacokinetic profiles of the hedgehog signaling antagonist cyclopamine in the mouse. Toxicol Sci 104(1): 189-197.

Liu Z, Zhang B, Liu K, Ding Z, Hu X (2012) Schisandrin B attenuates cancer invasion and metastasis via inhibiting epithelial-mesenchymal transition. PLoS One 7(7): e40480.

Louro ID, Bailey EC, Li X, South LS, McKie-Bell PR, Yoder BK, Huang CC, Johnson MR, Hill AE, Johnson RL, Ruppert JM (2002) Comparative gene expression profile analysis of GLI and c-MYC in an epithelial model of malignant transformation. Cancer Res 62(20): 5867-5873.

Maitah MY, Ali S, Ahmad A, Gadgeel S, Sarkar FH (2011) Up-regulation of sonic hedgehog contributes to TGF- $\beta 1$-induced epithelial to mesenchymal transition in NSCLC cells. PLoS One 6(1): e16068.

McMillan R, Matsui W (2012) Molecular pathways: the hedgehog signaling pathway in cancer. Clin Cancer Res 18(18): 4883-4888.

Monteleone F, Rosa R, Vitale M, D’Ambrosio C, Succoio M, Formisano L, Nappi L, Romano MF, Scaloni A, Tortora G, Bianco R, Zambrano N (2013) Increased anaerobic metabolism is a distinctive signature in a colorectal cancer cellular model of resistance to antiepidermal growth factor receptor antibody. Proteomics 13(5): 866-877.

Motzer RJ, Michaelson MD, Rosenberg J, Bukowski RM, Curti BD, George DJ, Hudes GR, Redman BG, Margolin KA, Wilding G (2007) Sunitinib efficacy against advanced renal cell carcinoma. J Urol 178(5): 1883-1887.

Mueller MT, Hermann PC, Witthauer J, Rubio-Viqueira B, Leicht SF, Huber S, Ellwart JW, Mustafa M, Bartenstein P, D'Haese JG, Schoenberg MH, Berger F, Jauch KW, Hidalgo M, Heeschen C (2009) Combined targeted treatment to eliminate tumorigenic cancer stem cells in human pancreatic cancer. Gastroenterology 137(3): 1102-1113.

Nakamura M, Tanaka H, Nagayoshi Y, Nakashima H, Tsutsumi K, Ohtsuka T, Takahata S, Tanaka M, Okada H (2012) Targeting the hedgehog pathway with interacting peptides to Patched-1. J Gastroenterol. 47(4): 452-460.

Nardone A, Corvigno S, Brescia A, D’Andrea D, Limite G, Veneziani BM (2011) Long-term cultures of stem/progenitor cells from lobular and ductal breast carcinomas under non-adherent conditions. Cytotechnology 63(1): 67-80.

Rini BI, Atkins MB (2009) Resistance to targeted therapy in renal-cell carcinoma. Lancet Oncol 10(10): 992-1000.

Rini BI, Small EJ (2005) Biology and clinical development of vascular endothelial growth factor-targeted therapy in renal cell carcinoma. J Clin Oncol 23: 1028-1043.

Rosa R, Marciano R, Malapelle U, Formisano L, Nappi L, D'Amato C, D’Amato V, Damiano V, Marfè G, Del Vecchio S, Zannetti A, Greco A, De Stefano A, Carlomagno C, Veneziani BM, Troncone G, De Placido S, Bianco R (2013) Sphingosine kinase 1 overexpression contributes to cetuximab resistance in human colorectal cancer models. Clin Cancer Res 19(1): 138-147.

Schneider T, Osl F, Friess T, Stockinger H, Scheuer WV (2002) Quantification of human Alu sequences by real-time PCR-an improved method to measure therapeutic efficacy of anti-metastatic drugs in human xenotransplants. Clin Exp Metastasis 19(7): 571-582.

Sekulic A, Migden MR, Oro AE, Dirix L, Lewis KD, Hainsworth JD, Solomon JA, Yoo S, Arron ST, Friedlander PA, Marmur E, Rudin CM, Chang AL, Low JA, Mackey HM, Yauch RL, Graham RA, Reddy JC, Hauschild A (2012) Efficacy and safety of vismodegib in advanced basal-cell carcinoma. N Engl J Med 366(23): 2171-2179.

Shigemura K, Huang WC, Li X, Zhau HE, Zhu G, Gotoh A, Fujisawa M, Xie J, Marshall FF, Chung LW (2011) Active sonic hedgehog signaling between androgen independent human prostate cancer cells and normal/benign but not cancer-associated prostate stromal cells. Prostate 71(16): 1711-1722.

Steg AD, Katre AA, Bevis KS, Ziebarth A, Dobbin ZC, Shah MM, Alvarez RD, Landen CN (2012) Smoothened antagonists reverse taxane resistance in ovarian cancer. Mol Cancer Ther 11(7): 1587-1597.

Teglund and Toftgård (2010) Hedgehog beyond medulloblastoma and basal cell carcinoma. Biochim Biophys Acta 1805(2): 181-208. 
Vokes SA, Yatskievych TA, Heimark RL, McMahon J, McMahon AP, Antin PB, Krieg PA (2004) Hedgehog signaling is essential for endothelial tube formation during vasculogenesis. Development 131(17): 4371-4380.

Yu J, Carroll TJ, McMahon AP (2002) Sonic hedgehog regulates proliferation and differentiation of mesenchymal cells in the mouse metanephric kidney. Development 129(22): 5301-5312.

Yue D, Li H, Che J, Zhang Y, Tseng HH, Jin JQ, Luh TM, Giroux-Leprieur E, Mo M, Zheng Q, Shi H, Zhang H, Hao X, Wang C, Jablons DM, He B (2014) Hedgehog/Gli promotes epithelial-mesenchymal transition in lung squamous cell carcinomas. J Exp Clin Cancer Res 33(1): 34.
Zhang L, Bhasin M, Schor-Bardach R, Wang X, Collins MP, Panka D, Putheti P, Signoretti S, Alsop DC, Libermann T, Atkins MB, Mier JW, Goldberg SN, Bhatt RS (2011) Resistance of renal cell carcinoma to Sorafenib is mediated by potentially reversible gene expression. PLoS One 6(4): e19144.

(c) (1) (2) (2) This work is licensed under the Creative Commons Attribution-NonCommercial-Share Alike 3.0 Unported License. To view a copy of this license, visit http://creativecommons. org/licenses/by-nc-sa/3.0/

Supplementary Information accompanies this paper on British Journal of Cancer website (http://www.nature.com/bjc) 